\title{
Consumo de Jornal Impresso e Online: Impresso é Status, Online é Facilidade
}

\author{
Newspaper Consumption in Print and Online: Printed Newspapers is Status and Online \\ is Easiness
} Instituto de Educação Superior de Brasília, Faculdade de Administração, Brasília, DF, Brasil ${ }^{3}$ 


\title{
Resumo
}

O jornal online tem demonstrado crescente utilização, podendo representar um potencial risco para o mercado de jornal impresso. Para investigar este mercado, o estudo objetiva avaliar como variáveis motivacionais (i.e., valores humanos e axiomas sociais) e os julgamentos afetivo e racional influenciam, comparativamente, o uso de jornal impresso e online. Para tanto, foi adotado o Modelo de Influência Cultural no Consumo (MICC). Foram conduzidas duas etapas com leitores de jornais impresso e online. Uma exploratória, para identificar atributos de jornal, com 11 entrevistas, e outra, por meio de um survey online $(\mathrm{N}=498)$, para avaliar as relações entre os construtos do modelo. As análises com Modelagem por Equações Estruturais, identificaram que o uso de jornal é diferente para cada modalidade. Para o jornal impresso, há uma relação afetiva com o produto, mediada pela preferência por jornal impresso. No jornal online, a relação é racional, sob a influência direta da preferência por jornal online. Destaca-se a originalidade da pesquisa ao verificar a perspectiva do consumidor de jornal, identificar idiossincrasias opostas entre as duas modalidades, além de trazer modelos comparativos para este mercado, englobando não apenas atributos de jornal, como aspectos subjetivos ligados ao consumo de jornal.

Palavras-chave: valores humanos; axiomas sociais; atributos; julgamento afetivo; julgamento fragmentado.

\begin{abstract}
Online newspapers are becoming increasingly popular and may pose a threat to the traditional print newspaper market. To investigate this market, this study aims to assess how motivational variables (i.e., human values and social axioms) and affective and rational judgments comparatively influence the use of print and online newspapers. Therefore, we have applied the Consumer Cultural Influence Model (CCIM) to this subject. Our research investigates print and online newspaper usage in two different ways. One is exploratory designed to identify newspaper attributes through 11 interviews, and the other uses an online survey $(\mathrm{N}=498)$ to evaluate the relationships between the model's constructs. The analyses conducted using structural equation modeling, demonstrate that the usage for each type of newspaper is different. Print newspapers involve affective judgment and the establishing of an emotional attachment to the product for those who have a preference for print newspapers. In terms of online newspapers, the relationship is rational for those who prefer online newspapers. The originality of this research has to do with its examination of the perspective of the newspaper consumer, and its identification of opposing idiosyncrasies associated with these differing preferences. It also applies comparative models to this market, dealing not only with newspaper attributes, but also subjective aspects linked to newspaper consumption.
\end{abstract}

Keywords: human values; social axioms; product attributes; affective judgment; piecemeal judgment.

JEL code: L82, L86, E21. 


\section{Introdução}

As mudanças tecnológicas ocorridas no final do século XX e início do século XXI, sobretudo o surgimento e difusão da internet, causaram profundos impactos na indústria da comunicação. As mídias online impactaram sobremaneira a indústria de mídia global, nacional e localmente (Skogerbø \& Winsvold, 2011). Um dos setores que mais sofreu impacto foi o setor de jornais (Flavián \& Gurrea, 2009). Entre as mudanças promovidas pela internet na indústria de jornal é destaque o jornal online, que tem demonstrado crescente utilização, representando um risco para o mercado de jornal impresso (Thurman, 2018; Thurman \& Fletcher, 2017). Ou seja, um contexto que instiga estudos mais profundos sobre o mercado de jornais.

Algumas pesquisas com foco na produção de conteúdo noticioso para essas duas modalidades de produto, impresso e online, já foram conduzidas. Dentre elas, pode-se mencionar investigações quanto ao processo de canibalização de um pelo outro (Deleersnyder, Geyskens, Gielens, \& Dekimpe, 2002, Flavián \& Gurrea, 2007; Gentzkow, 2007); aos efeitos na cadeia de produção (Deleersnyder, Dekimpe, Sarvary, \& Parker, 2004; Ghosh, 1998; Gilbert, 2001) e ao comportamento de consumo nas duas modalidades do produto. Dentre as pesquisas posicionadas sob a perspectiva do consumidor, nota-se uma predominância de estudos sobre as motivações do consumo de jornal (Flavián \& Gurrea, 2007, 2009; Lin, Salwen, \& Abdulla, 2005; Mings, 1997), com maior destaque para a investigação de motivação de leitura de jornais online.

Cabe destacar que o consumo de jornais vem sendo tratado, muitas vezes, sob o enfoque de escolha de um meio de comunicação, predominantemente estudado a partir das abordagens da hipótese de usos e gratificações e da teoria da difusão da inovação (Chyi \& Lasorsa, 1999), que se mostram limitadas quanto à investigação de aspectos motivacionais de consumo. Assim, na ausência de um modelo geral para investigação das motivações sobre o consumo de jornal (Flavián \& Gurrea, 2009), o modelo das duas rotas (MDR), proposto por Allen e Ng (1999) mostra-se promissor.

O MDR (Allen \& Ng, 1999), já foi testado em diversos mercados (e.g., automóveis, serviços educacionais, óculos de sol, itens alimentícios, pacotes de viagem, partidos políticos, destino turístico, dentre outros) e revela-se adequado para a análise do consumo de jornais, pois investiga a influência de aspectos motivacionais como valores humanos de Schwartz (1992) sobre o consumo de produtos ou serviços (Alfinito, Siqueira, \& Torres, 2016; Castro, Torres, Nascimento, \& Demo, 2015; Pimenta \& Piato, 2016). Adicionalmente, o MDR permite analisar aspectos intrínsecos ao sistema de escolha do consumidor, por duas rotas, uma direta e outra indireta, que são mediadas pelo construto que Allen (2000) denominou como julgamento e significado do produto. Este constitui quatro fatores: julgamento afetivo, significado simbólico, julgamento fragmentado e significado utilitário. Assim, a rota direta envolve as opções mais afetivas do consumidor (julgamento afetivo e significado simbólico), ativadas pelo que Kahneman (2011) chama de sistema 1 do processamento cognitivo. Quanto às opções mais racionais do consumidor (julgamento fragmentado e significado utilitário), estas são ativadas pelo que Kahneman designa como sistema 2 (a rota indireta do MDR).

Complementarmente ao MDR, Alfinito e Torres (2012) propuseram a inclusão de outro construto motivacional ao modelo, os axiomas sociais, que apresentaram uma relevante melhoria na predição de comportamentos sociais, quando combinados aos valores humanos (Bond, Leung, Au, Tong, \& Chemonges-Nielson, 2004). O modelo com a integração dos axiomas sociais ao MDR, também promissor no contexto de escolha do consumidor, foi designado como modelo de influência cultural no consumo (MICC) (Alfinito \& Torres, 2012). Neste sentido, baseado no MDR expandido, o MICC, o objetivo desta pesquisa é ampliar o entendimento quanto ao uso de jornal, investigando como variáveis motivacionais (i.e., valores humanos e axiomas sociais) e os julgamentos afetivo e racional influenciam a frequência de uso de jornal online e de uso de jornal impresso. De maneira específica, busca-se identificar uma escala de avaliação de atributos de jornal; bem como analisar as forças das rotas direta (afetiva) e indireta (racional) sobre a frequência de uso de jornal online, comparativamente ao uso de jornal impresso, perpassando aspectos relacionados à preferência por jornal (impresso ou online). 


\section{O Modelo das Duas Rotas e seus Elementos}

No âmbito do comportamento do consumidor, o construto motivacional de valores humanos tem sido adotado para explicar a preferência e a escolha de diferentes produtos ou serviços (Alfinito et al., 2016; Porto \& Torres, 2014; Strasheim \& Ungerer, 2017), por apresentar estrutura geral de crenças com considerável grau de universalidade (Chen et al., 2016). Dessa forma, a utilização de valores humanos como preditor do comportamento de consumo ganhou novos desdobramentos a partir do estudo de Allen e $\mathrm{Ng}$ (1999) com o modelo das duas rotas (MDR), por exemplo.

A força dos valores humanos no contexto de consumo pode ser explicitada por sua própria definição. De acordo com Schwartz (1992), a priorização de valores individuais afeta as experiências sociais, as orientações comportamentais e as ações dos indivíduos. A estrutura dos valores pode ser considerada como a estrutura da motivação humana e eles são considerados como princípios orientadores transituacionais, que variam em importância para os indivíduos e que podem explicar as decisões, atitudes e comportamento das pessoas (Sagiv, Roccas, Cieciuch, \& Schwartz, 2017).

Inicialmente, Schwartz (1992) identificou dez tipos motivacionais na predição de comportamentos sociais, organizados em quatro dimensões de segunda ordem, dispostas em dois eixos (autotranscendência versus autopromoção e abertura à mudança versus conservação). No entanto, estudos mais recentes sugeriram a possibilidade de existência de subtipos motivacionais adicionais (Cieciuch \& Schwartz, 2012), resultando na teoria de valores refinada, apontando uma estrutura com 19 tipos motivacionais (Schwartz et al., 2012).

Inspirados na estrutura motivacional disponível com os valores humanos, na predição de comportamentos sociais que eles poderiam oferecer, bem como no modelo multi-atributo da teoria da expectância de Fishbein e Ajzen (1975), a partir de subsistemas que ampliam a explicação geral de valores - atitude - comportamento Fishbein, surge o MDR (Allen, Ng, \& Wilson, 2002).

Para Fishbein e Ajzen (1975), a expectância sobre um objeto é formada a partir de uma atitude total, que é resultado da somatória das atitudes estimadas dos atributos que compõem o objeto. Os atributos, na situação de consumo, são características intrínsecas dos produtos ou das marcas a partir das quais os consumidores avaliam as alternativas entre produtos e ofertas. Allen e $\mathrm{Ng}$ (1999) observa que alguns teóricos cujos trabalhos se apoiam na abordagem do modelo de multi-atributos com origens na teoria da expectância atribuem papel insignificante aos valores humanos nos processos de avaliação e escolha de produtos, ao considerarem que esses construtos exercem uma influência mínima na avaliação de objetos específicos.

Assim, o MDR desvenda o papel dos valores humanos na avaliação de produtos. A crença e a avaliação da importância dos atributos se combinam para determinar a preferência por um produto (Torres \& Allen, 2009a). A avaliação dos atributos é influenciada pelos valores humanos dada à capacidade dos atributos reforçarem metas de longo prazo e atenderem a padrões de objetivos tangíveis, envolvendo assim um julgamento fragmentado em relação ao objeto e uma avaliação do seu significado utilitário. Esta é rota indireta do MDR. No entanto, essa influência pode não ocorrer apenas de maneira racional. Deste modo, Allen e Ng (1999) propõem que seja considerada também uma avaliação afetiva e holística em relação ao objeto, sob a influência dos valores em relação ao julgamento afetivo quanto ao objeto e seu significado simbólico, que eles designaram como rota direta.

Como mencionado, o MDR incorpora em sua proposta o conceito de julgamento e significado do produto, que é composto por quatro fatores: julgamento afetivo, julgamento fragmentado, significado simbólico e significado utilitário. Para Mittal (1988), o julgamento afetivo é uma escolha importante na hora da formação de preferência e possui a característica de ser processado de forma emotiva, considerando mais conceitos abstratos do que o resultado da avaliação lógica, orientada e sistemática dos atributos tangíveis.

Trata-se, portanto, de uma composição de valor adquirido referente a outros aportes da concepção

RAC, Rio de Janeiro, v. 23, n. 1, art. 2, pp. 23-42, janeiro/fevereiro, 2019, http://rac.anpad.org.br (a) 
humana, tais como história pessoal e comunitária, experiência prévia acerca do objeto, significados culturais, valores sociais e outros (Castro et al., 2015). Estes aspectos são importantes na construção do apelo do produto ou serviço junto ao segmento populacional dirigido - e mesmo como recurso para a combinação de diferentes segmentos (Torres \& Allen, 2009b).

Ainda de acordo com Mittal (1988), uma das principais características do julgamento afetivo é ser holístico, intuitivo, imediato, influenciado pelos componentes particulares do indivíduo, e, assim, mais difícil de se descrever. Este contexto traz em si o desafio inerente ao do julgamento afetivo, qual seja, descrever e pontuar os processos individuais internos de avaliação pessoal de cada consumidor sobre aquele produto (Zajonc, 1980).

Observa-se que o julgamento afetivo se dá por processos subjetivos. O julgamento fragmentado, todavia, envolve um processamento passo-a-passo, racional, analítico, lógico, elencando fatores como utilidade, aplicabilidade e custo-benefício, dentre outros (Wegener, Petty, Blankenship, \& DetweilerBedell, 2010). Assim, é fundamentado nos atributos tangíveis e nas suas funções utilitárias ligadas à escolha, culminando na avaliação das alternativas, com a melhor combinação possível para obter o melhor resultado para determinada situação (Luppe \& De Angelo, 2010).

Allen (2000) argumenta que o consumidor julga atributo por atributo, exigindo conhecimento acerca das consequências e desdobramentos do produto avaliado. Esse julgamento fragmentado ocorre de forma orientada e sistemática, para somente depois avaliar o produto como um todo (Castro et al., 2015).

Com relação aos significados, simbólico ou utilitário, o primeiro é subjetivo e tem forte relação com as crenças e emoções do indivíduo. Fundamentado em atributos intangíveis e externos ao produto ou serviço, leva em consideração todo o contexto social e cultural que o consumidor está inserido (Demo \& Guanabara, 2015). Consiste em uma construção de sentido que desloca o foco do objeto em direção ao consumidor e, principalmente, às suas expectativas e perspectivas idiossincráticas (Richins, 1994). De acordo com Allen (2000), o significado simbólico compõe a rota direta do MDR, saindo dos valores pessoais e passando por um julgamento necessariamente afetivo e intuitivo com duas principais características: desenvolver e expressar o autoconhecimento e identidade do indivíduo (Torres \& Allen, 2009a).

O significado utilitário, por sua vez, é atribuído e fundamentado na sua proficuidade, aspecto diretamente ligado aos atributos tangíveis - como conveniência, praticidade, eficiência, valor de troca, etc. É, basicamente, a percepção do consumidor ligada às funções do produto (Allen, 2000). Assim, o significado utilitário exige que o indivíduo julgue de forma racional e objetiva cada atributo daquele produto para que, desta forma, seja formado o seu significado utilitário global (Alfinito, Nepomuceno, $\&$ Torres, 2012).

Tem-se, portanto, o panorama conceitual do MDR, com suas duas rotas: uma direta, partindo dos valores humanos, que alimentam o julgamento afetivo para a atribuição de significados simbólicos do produto; outra indireta, também partindo dos valores humanos, que propiciam a avaliação dos atributos do produto, por meio do julgamento fragmentado para a atribuição de significados utilitários do produto.

\section{Os Axiomas Sociais e o Modelo de Influência Cultural no Consumo}

Assim como os valores humanos, os axiomas sociais objetivam compreender o comportamento humano. Leung et al. (2002) propõem que os axiomas permitem alcançar explicações sobre o comportamento e diferenças culturais que não são captadas pelos valores humanos. Leung e Bond (2008) apontam que o objetivo da proposição do construto é aumentar a descrição e interpretação da cultura e do comportamento em relação à explicação fornecida pelo construto valores humanos.

Deste modo, os axiomas sociais são definidos como crenças generalizadas sobre pessoas, grupos

RAC, Rio de Janeiro, v. 23, n. 1, art. 2, pp. 23-42, janeiro/fevereiro, 2019, http://rac.anpad.org.br (cc) 
sociais, instituições sociais, o ambiente físico, ou o mundo espiritual, bem como sobre as categorias de eventos e fenômenos no mundo social. Estas crenças generalizadas são codificadas na forma de uma afirmação sobre a relação entre duas entidades ou conceitos (Leung \& Bond, 2008). Sua estrutura envolve cinco dimensões: ceticismo social, controle do destino, recompensa por empenho, complexidade social e religiosidade.

O construto denota uma característica mais descritiva em relação aos valores humanos, capaz de oferecer uma opção de triangulação aos valores (Leung et al., 2002). Essa abordagem foi utilizada inicialmente por Bond, Leung, $\mathrm{Au}$, Tong e Chemonges-Nielson (2004) que testou a utilização combinada desses dois construtos na predição do comportamento relacionado à três tendências comportamentais: estilo de resolução de conflitos, formas de enfrentamento e interesses vocacionais. Os resultados indicaram que, apesar de haver correlação entre algumas dimensões de axiomas e tipos motivacionais, os dois construtos não se sobrepõem. Bond et al. (2004) reforçam que os construtos avaliam aspectos diferentes, mas que a utilização em conjunto oferece uma possibilidade de alcançar resultados significativos que normalmente não ocorreriam ao utilizar apenas um deles. Contribuições posteriores (Chen et al., 2016; Leung et al., 2007) confirmam a complementaridade entre os construtos.

Assim, a combinação de axiomas sociais e valores humanos potencializa a predição de comportamentos sociais, inclusive os de consumo. Nesta perspectiva, ampliando o modelo das duas rotas, Alfinito e Torres (2012) avaliaram a escolha do consumidor associando aos valores humanos, o construto de axiomas sociais. Os resultados foram bastante promissores, com aumento da predição nas duas rotas, com destaque para a rota direta. A melhora na predição pode ser atribuída à característica dos axiomas sociais que comparativamente aos valores humanos, é mais descritivo e, por isso, estaria mais acessível à cognição e mais próximo à realidade dos atributos (Alfinito et al., 2016). Consequentemente, os axiomas sociais exerceriam um papel de organização do sistema de crenças das pessoas, cumprindo a função de facilitar a relação entre as pessoas e o contexto em que estão inseridas (Leung et al., 2012).

Esse modelo com axiomas sociais, na perspectiva do consumidor, foi designado como modelo de influência cultural no consumo (MICC). Todos seus demais elementos constituintes são os mesmos que o MDR. Ou seja, há uma rota direta que sai de valores humanos associados a axiomas sociais, em direção aos significados simbólicos do produto, por meio do julgamento afetivo. A outra rota, indireta, também se origina na combinação de valores humanos e axiomas sociais, passando pela avaliação dos atributos tangíveis evidenciados pelos significados utilitários do produto, por meio do julgamento fragmentado.

\section{O MICC e o Consumo de Jornal}

Apesar da escassez de estudos que explorem o uso de jornal, a perspectiva de usos e gratificações, fundamenta-se na premissa que a audiência persegue a satisfação de necessidades individuais e sociais nos meios de comunicação que podem expressar-se em termos de motivação (Mcquail, 2004; Mings, 1997). Tem-se ainda que as pessoas suportam os meios de comunicação que apoiam ou reforçam suas crenças, e que promovam seus interesses (Bitner, 1989; Rogers, 2003). Dessa forma, o MICC, apresentado na Figura 1, parece ser um modelo suficientemente robusto, com variáveis motivacionais (valores humanos) e crenças (axiomas sociais), que permitem avaliar o comportamento de leitura de jornal. 


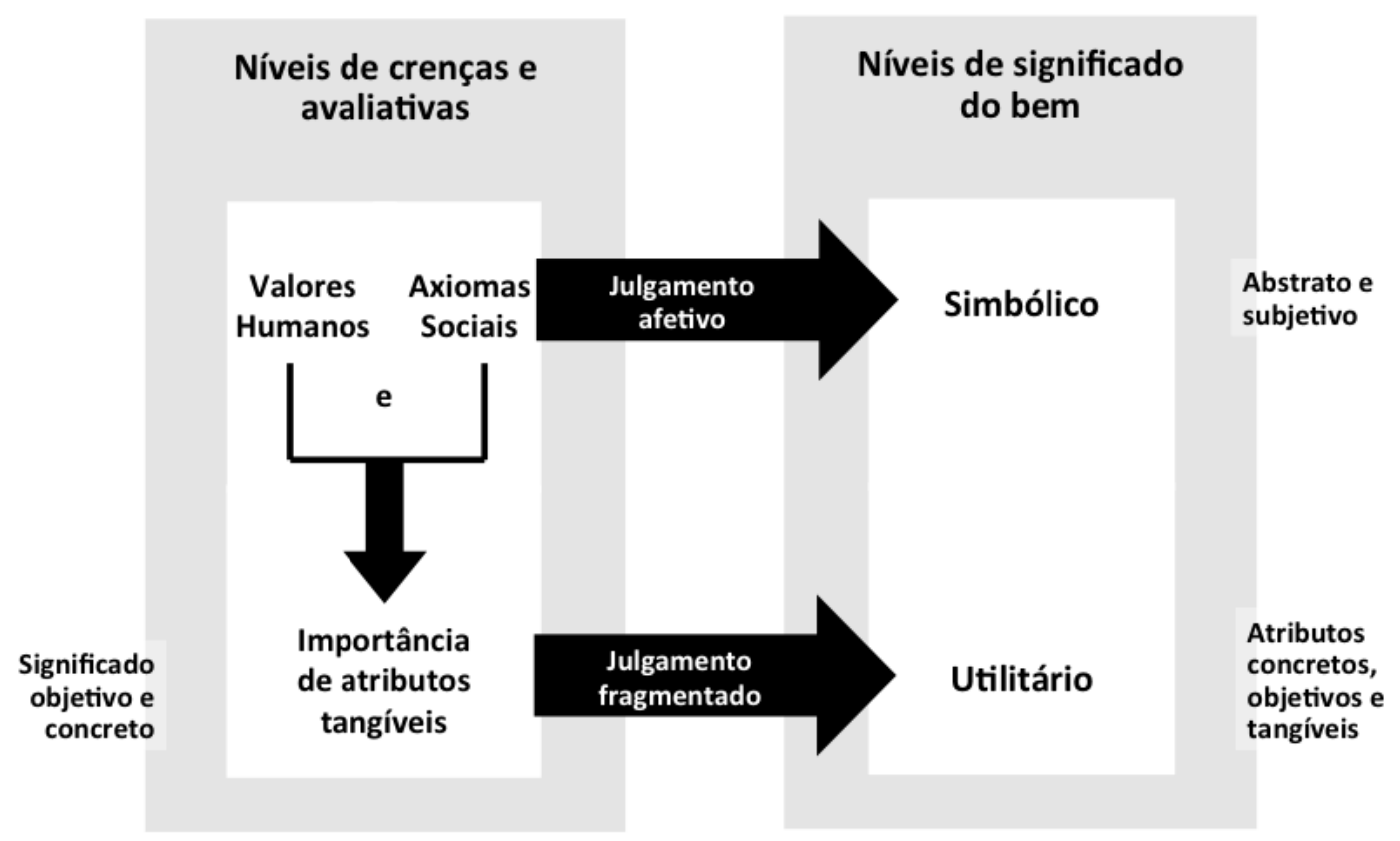

Figura 1. Modelo de Influência Cultural no Consumo

Fonte. Modelo proposto por Alfinito, S., \& Torres, C. V. (2012). Modelo de influência cultural no consumo: Uma proposta baseada em axiomas sociais. Revista de Administração Mackenzie, 13(5), 15-38. http://doi.org/10.1590/S167869712012000500002

Assim, partindo-se do MICC, o modelo de pesquisa congrega construtos psicossociológicos que podem oferecer um entendimento mais aprofundado sobre os fatores que influenciam o uso do jornal como fonte de informação. Essa abordagem mais ampla vai ao encontro do que Mitchelstein e Boczkowski (2010) observam ser necessário para abordar o fenômeno a partir de várias perspectivas, incorporando o comportamento ao contexto social; e do que Chyi e Lee (2013) reconhecem como uma necessidade: compreender o consumo de jornal online a partir de modelos que congreguem diferentes resultados empíricos de uma só vez, por meio de abordagens mais holísticas. Estas podem ser acessadas pela rota direta no MICC.

Considerando o quão recente é o jornal online, se comparado ao jornal impresso, é relevante destacar que as investigações empíricas atentam para o fato de haver uma relação ambígua a respeito da preferência por um formato de mídia determinado. Uma série de levantamentos (Chyi, 2012; Chyi \& Chang, 2009; Chyi \& Lasorsa, 1999; Chyi \& Lee, 2013) identificaram que a maioria das pessoas preferem o formato impresso ao online, quando considerados o mesmo conteúdo e o mesmo preço. Os estudos de motivação conduzidos no paradigma de usos e gratificações, indicam que essa relação pode ocorrer pelo fato de que algumas funções utilitárias do jornal impresso não são percebidas no jornal online (Skogerbø \& Winsvold, 2011). Todavia, não houve a exploração das funções simbólicas do jornal, que poderiam ser melhor percebidas na modalidade online, por exemplo. Assim, se as funções utilitárias são ativadas pelo julgamento fragmentado (Allen, 2000) e as simbólicas pelo julgamento afetivo (Alfinito et al., 2012), resta investigar como este movimento ocorre para cada modalidade de jornal, online e impresso.

Quanto à preferência, Chyi e Lee (2013) identificam uma conclusão convergente: o jornal online é percebido como uma alternativa menos desejada em relação aos jornais impressos. Para os autores o fato de nem sempre as pessoas usarem aquilo que preferem é reconhecido, porém, os autores alertam que esse resultado pode ser reflexo de os jornais online serem um fenômeno que ainda se encontra em crescimento. A preferência é um construto largamente empregado no campo do comportamento do consumidor como determinante do comportamento. Assim, baseado nas evidências empíricas e em pressupostos teóricos é esperado que tanto preferência por jornal impresso, quanto preferência por jornal online impactem no uso de jornal online, por exemplo. 
O modelo geral da pesquisa, baseado no MICC (Alfinito \& Torres, 2012), agrega as variáveis que vêm sendo objeto de diversos estudos que abordam o fenômeno de uso do jornal em todo o mundo. São elas: preferência por uso de jornal impresso, preferência por uso de jornal online, frequência de uso de jornal impresso, frequência de uso de jornal online. Nesta pesquisa, tais variáveis são testadas em adição ao MICC, cuja estrutura teórico-conceitual foi apresentada na Figura 1.

\section{Método}

Para que fossem investigadas as relações entre as principais variáveis que interferem no consumo de jornal foram realizadas duas etapas complementares, a etapa 1 , exploratória, e a etapa 2 , quantitativa e correlacional.

A etapa 1 consistiu na construção da Escala de Avaliação de Atributos de Jornal, com uma etapa de entrevistas para o levantamento dos itens de atributos para a escala e outra de validação semântica e por seus juízes. Na etapa de entrevistas, o critério de recrutamento foi que o entrevistado fosse assinante e leitor de jornal impresso ou jornal online. Buscou-se entrevistar pessoas que tivessem o hábito de comprar e ler o jornal nas modalidades, impressa e online. Foram conduzidas entrevistas em profundidade com 11 pessoas (4 mulheres e 7 homens), com idades entre 26 e 67 anos e de diferentes ocupações laborais. Todos os entrevistados tinham nível superior completo ou em curso. Na nona entrevista foi alcançada a saturação teórica e foram conduzidas mais duas entrevistas. As entrevistas foram transcritas e analisadas por análise de conteúdo, com detalhamento descrito na seção de resultados. Os resultados permitiram a construção de uma lista de atributos de jornais. Seguindo as recomendações de Pasquali (2005), ao final das verificações semântica e de juízes, a lista de atributos resultou na Escala de Avaliação de Atributos de Jornal, com 39 itens, adotada na etapa 2 do estudo.

A etapa 2 consistiu na testagem do modelo teórico-conceitual (Figura 1), acrescido das variáveis específicas de preferência e uso de jornal, por modalidade, online e impresso. Por meio de um survey, foram coletados 754 questionários, restando 498 para as análises iniciais, após a exclusão de questionários incompletos e casos extremos multivariados pelo cálculo da distância Mahalanobis. A amostra compreendeu consumidores com idades entre 14 e 73 anos ( $M=35,37 ; \mathrm{DP}=11,27)$, sendo 51,4\% de mulheres e 83,6\% com ensino superior completo. Em relação à frequência de leitura das modalidades impressa e online, a amostra foi dividida em grupos, nos quais se considerou como tendo alta frequência de leitura aqueles participantes que declararam ler entre 5 e 7 vezes na semana cada uma das modalidades e como tendo baixa frequência de leitura os que liam até 4 vezes por semana.

$\mathrm{O}$ instrumento foi administrado online, com a seguinte instrução inicial: Considere em suas respostas apenas jornais que abordem assuntos variados e que não sejam distribuídos gratuitamente, seguindo recomendação de Mitchelstein e Boczkowski (2010) para que o comportamento de leitura de jornais de ampla abordagem não fosse comparado com o comportamento de leitura de jornais segmentados ou gratuitos, já que estes são produtos diferentes daqueles e cumprem outras funções de leitura.

Após esta instrução, foi solicitado que os participantes identificassem por meio de respostas dicotômicas se seu comportamento de leitura se enquadrava na situação descrita: (a) li jornal impresso nos últimos sete dias; (b) li jornal em tablets ou visitei sites de jornais nos últimos sete dias. Este critério de leitura na última semana segue o adotado no mercado brasileiro pelos principais institutos de pesquisa de consumo de mídia, como Ipsos Marplan (2017) e IBOPE Inteligência (2017), para definir um leitor habitual de jornal. Os participantes cujas respostas mostraram-se afirmativas foram conduzidos à etapa seguinte do instrumento e os que responderam negativamente foram conduzidos a uma tela de agradecimento, sendo dispensados da pesquisa.

Em seguida, foram apresentadas quatro escalas e o comportamento de consumo de jornal nas modalidades impressa e online. As escalas foram apresentadas aos participantes na seguinte ordem: 
Escala de Avaliação de Atributos de Jornal (resultante da etapa 1); Escala de Julgamento e Significado de Produto (Alfinito et al., 2012); Escala de Axiomas Sociais (Alfinito \& Torres, 2012); e Questionário de Valores Refinado, do inglês Portrait Values Questionnaire - Refined (PVQ-R) (Torres, Schwartz, \& Nascimento, 2016).

Os atributos de jornal foram avaliados por escala de importância tipo Likert de seis pontos, variando entre 1 (nada importante) e 6 (muito importante). Os respondentes dispunham do item NSA (não se aplica) e foram instruídos a preenchê-lo, caso o atributo não se aplicasse à modalidade de leitura de jornal que realizavam. As respostas com esta marcação foram consideradas como dados omissos na fase de tratamento dos dados.

A Escala de Julgamento e Significado de Produto adotada foi a validada por Alfinito, Nepomuceno e Torres (2012) para o Brasil, composta por 20 itens, que foram avaliados em escala tipo Likert de seis pontos, variando entre 1 (discordo totalmente) e 6 (concordo totalmente). Para valores humanos, foi escolhido o PVQ-R, por ser o instrumento proposto no refinamento da teoria de valores (Schwartz et al., 2012) e por oferecer uma melhor discriminação dos tipos motivacionais. A escala validada para o Brasil por Torres, Schwartz e Nascimento (2016), é composta por 57 itens e mostrou-se mais adequada para acessar os tipos motivacionais adjacentes. Ela foi avaliada em escala tipo Likert de seis pontos, variando entre 1 (não se parece nada comigo) e 6 (se parece muito comigo).

A Escala de Axiomas Sociais de Alfinito e Torres (2012) foi adotada na versão reduzida validada por Assumpção (2013) e composta por 25 itens. Os itens foram avaliados em escala tipo Likert de seis pontos, variando entre 1 (desacredito fortemente) e 6 (acredito fortemente). Por fim, foram apresentadas questões sócio demográficas (UF, idade, sexo, renda familiar, escolaridade), para caracterizar a amostra.

Ao todo, o instrumento contou com 171 itens, sendo 141 das escalas apresentadas e 30 itens dos blocos de caracterização do comportamento de leitura e preferência por jornal e de questões sócio demográficas.

O instrumento, auto-aplicável, foi construído na plataforma SurveyMonkey e disponibilizado online durante 25 dias consecutivos. A amostragem foi não-probabilística, por conveniência e autogerada, com recrutamento dos participantes pela divulgação do link da pesquisa por email e publicação do link da pesquisa nas redes sociais Twitter e Facebook. De acordo com estudo de Rife, Cate, Kosinski e Stillwell (2016) quanto a amostragem via redes sociais, o uso de redes sociais como o Facebook é viável e promissor para a coleta de dados em ciências sociais, com resultados comparáveis aos obtidos por participantes recrutados por outros meios.

\section{Resultados}

A etapa 1 da pesquisa, envolvendo construção da escala de avaliação de atributos de jornal consistiu em uma análise de conteúdo conforme orientações de Gibbs (2008), por codificação linha a linha, e permitiu que fosse gerada uma lista de atributos utilizados pelos consumidores para avaliar tanto jornais impressos, como jornais online. A lista resultante da etapa de entrevistas em profundidade foi de 39 itens. Os itens foram submetidos à análise fatorial exploratória (AFE) (Hair, Black, Babi, Anderson, \& Tatham, 2009), observando as recomendações de Pasquali (2005) para o uso do método dos eixos principais (PAF) com rotação oblimin e promax. Esta última mostrou-se mais adequada ao construto. Para o corte das cargas fatoriais, foram considerados aceitáveis os valores a partir de 0,45 (Hair et al., 2009), resultando em uma estrutura de dois fatores, Notícias (16 itens, $\alpha=0,91)$ e Entretenimento (3 itens, $\alpha=0,77)$, com KMO de 0,92 e variância explicada de 45\%. Assim, a escala resultou em 19 itens.

De posse dos atributos, o modelo de pesquisa (Figura 1), foi testado em duas versões, uma para jornal online e outra para jornal impresso, por modelagem por equações estruturais. Primeiramente, foram computados os escores fatoriais para valores humanos, axiomas sociais, julgamento e significado do produto. Para a Escala de Avaliação de Atributos foram utilizados os fatores oriundos da AFE 
relatada na etapa 1. Para análise dos resultados das Análises Fatoriais Confirmatórias (AFCs) conduzidas e dos modelos estruturais, foram considerados os critérios propostos por Kline (2015).

Em seguida, foram empregadas as recomendações de Marôco (2010) e Hill e Hill (2008) que sugerem que o tamanho da amostra para o cálculo siga a proporção de variáveis observadas no modelo com, no mínimo, cinco observações para cada variável manifesta e, preferencialmente, mais de dez, para se garantir variabilidade suficiente para estimar os parâmetros do modelo. Assim, a amostra ( $\mathrm{N}=498)$ foi submetida a uma análise com recorte ainda mais rigoroso em relação aos casos omissos, sendo retirados todos os respondentes que apresentaram qualquer dado omisso (método listwise), resultando em uma amostra de 284 respondentes nos modelos estruturais finais, com 26 variáveis manifestas $(10,92$ respondente para cada variável) atendendo a sugestão de Marôco (2010).

Para atingir os objetivos da pesquisa, a estrutura do modelo conceitual, baseado no MICC, foi testada para dois cenários, com o uso do módulo AMOS do SPSS para modelagem por equações estruturais. $\mathrm{O}$ primeiro, para a avaliação da frequência de uso de jornal impresso, perpassando à preferência por uso de jornal impresso, resultou no Modelo estrutural 1. O segundo, para a avaliação da frequência de uso de jornal online, perpassando à preferência pelo uso de jornal online, resultou no Modelo estrutural 2.

Os dois cenários permitiram comparar a existência de idiossincrasias relativas ao consumo de cada modalidade de jornal, online e impresso. Os resultados dos modelos estruturais finais, com indicadores padronizados e estimativas significativas, são apresentados nas Figuras 2 (Modelo estrutural 1) e 3 (Modelo estrutural 2). Os índices de ajuste dos modelos estruturais 1 (Impresso) e 2 (Online) são resumidos na Tabela 1.

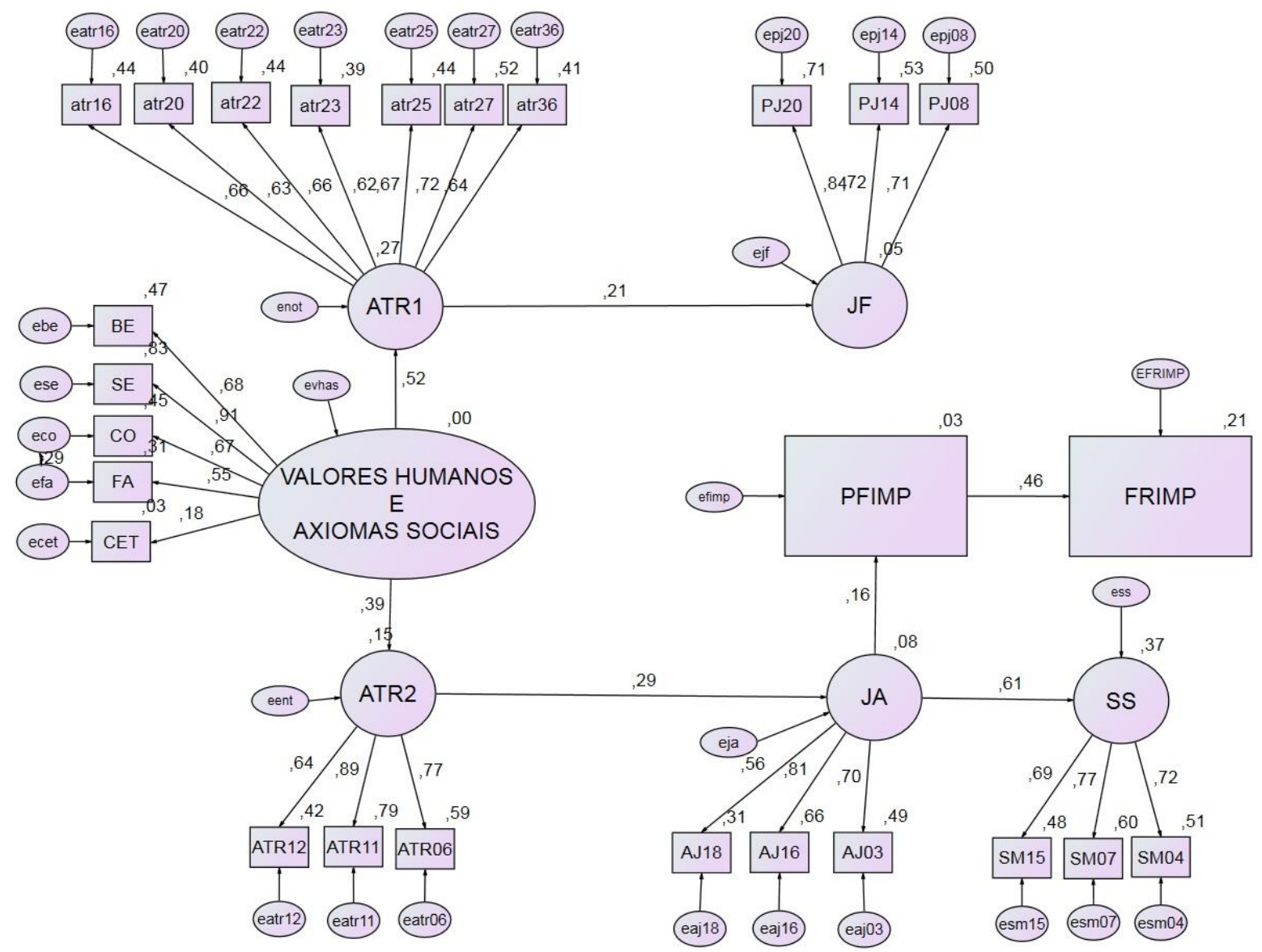

Figura 2. Modelo Estrutural 1 para a Avaliação do MICC na Variável Frequência de Uso de Jornal Impresso ATR1=atributos de jornal (fator notícias); ATR2=atributos de jornal (fator entretenimento); JA=julgamento afetivo; $\mathrm{JF}=$ julgamento fragmentado; $\mathrm{SS}=$ significado simbólico; $\mathrm{SU}=$ significado utilitário; PFIMP=preferência por uso de jornal impresso; FRIMP=frequência de uso de jornal impresso. 


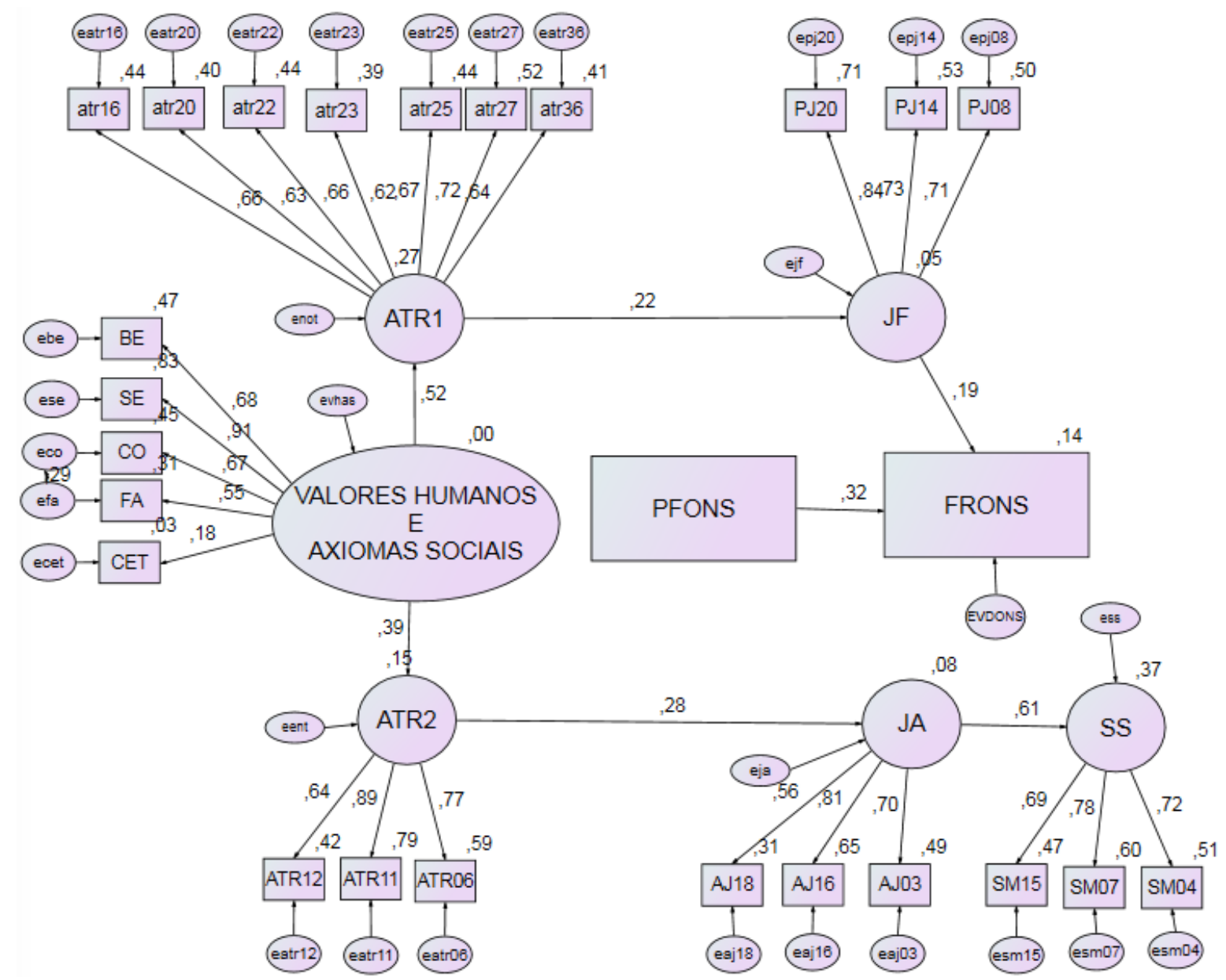

Figura 3. Modelo Estrutural 2 para a Avaliação do MICC na Variável Frequência de Uso de Jornal Online

ATR1=atributos de jornal (fator notícias); ATR2=atributos de jornal (fator entretenimento); JA=julgamento afetivo; $\mathrm{JF}=$ julgamento fragmentado; SS=significado simbólico; $\mathrm{SU}=$ significado utilitário; PFONS=preferência por uso de jornal online; FRONS=frequência de uso de jornal online.

Tabela 1

Índices de Ajuste dos Modelos de Consumo de Jornal Impresso (1) e Online (2)

\begin{tabular}{lcccc}
\hline Modelo & QUI $^{2}$ & CMIN/DF & CFI & RMSEA \\
\hline 1 Impresso & 533,35 & 1,82 & 0,902 & 0,054 \\
\hline 2 Online & 524,21 & 1,78 & 0,904 & 0,053 \\
\hline $\begin{array}{l}\text { Recomendação da } \\
\text { literatura (Marôco, } \\
\text { 2010) }\end{array}$ & $\begin{array}{c}\text { Quanto menor, } \\
\text { melhor }\end{array}$ & $\begin{array}{c}\text { Valores entre 2 e 5 } \\
\text { aceitáveis e } \\
\text { inferiores a 2 bons }\end{array}$ & $\begin{array}{c}\text { Maior ou igual a } \\
0,90\end{array}$ & $\begin{array}{c}\text { Bom abaixo de 0,08 } \\
\text { e muito bom abaixo } \\
\text { de 0,05 }\end{array}$ \\
\hline
\end{tabular}

Inicialmente, é importante destacar que nos dois modelos, dos 19 fatores de valores humanos previstos na teoria e testados, apenas quatro permaneceram como determinantes: benevolência (BE), segurança (SE), conformidade (CO) e face (FA). De axiomas sociais, a representatividade foi menor, com apenas um fator significativo, que foi o de ceticismo social (CET), dentre os cinco fatores da teoria.

O modelo conceitual da pesquisa, baseado no MICC (Figura 1), previa que os construtos de valores humanos e axiomas sociais se relacionariam com os construtos de julgamento fragmentado por intermédio dos atributos e que se relacionariam diretamente com o construto julgamento afetivo, constituindo, respectivamente, as rotas, direta e indireta. Todavia, essa estrutura confirmou-se 
parcialmente, nos dois modelos estruturais, já que não houve rota direta em nenhum deles. Os atributos formaram uma estrutura bi-fatorial e as duas rotas foram indiretas, cada uma passando por um fator diferente de atributos. Apesar de serem duas rotas indiretas, as suas características de racionalidade e afetividade foram mantidas, mas uma delas perdeu a força a depender da modalidade de jornal.

Nos dois modelos, a rota racional, emergiu de valores humanos e axiomas sociais em direção ao julgamento fragmentado, mediada totalmente pelo fator notícias dos atributos de jornal. O significado utilitário não foi significativo e foi suprimido do modelo. A rota afetiva, também partindo de valores humanos e axiomas sociais, seguiu até o julgamento afetivo, mediada totalmente pelo fator entretenimento dos atributos de jornal. O significado simbólico se manteve no modelo, sendo explicado pelo julgamento afetivo. Assim, quanto ao MICC, as relações esperadas para os construtos de julgamento afetivo e significado simbólico se confirmaram, mas para julgamento fragmentado e significado utilitário, elas não se confirmaram.

No modelo estrutural 1, para a previsão quanto à frequência de uso de jornal impresso, a rota racional não teve importância direta, mas a rota afetiva influenciou positivamente o uso de jornal impresso, com mediação total da preferência por jornal impresso. Assim, o fator entretenimento dos atributos de jornal e o julgamento afetivo se demonstraram determinantes para o consumidor de jornal impresso. Foi testada, ainda, a influência das variáveis de preferência e uso de jornal online sobre o jornal impresso, mas elas não foram relevantes.

Com relação ao modelo estrutural 2, para a previsão quanto à frequência de uso de jornal online, a rota afetiva foi a que não teve importância direta no modelo, e a racional foi a determinante para o uso de jornal online. Desta forma, o fator notícias dos atributos de jornal e o julgamento fragmentado mostraram-se importantes para o consumidor de jornal online. Todavia, a mediação de preferência por jornal (online) não mediou esta relação, como identificado para o jornal impresso. Apesar de haver uma influência direta de preferência por jornal online sobre a frequência de uso de jornal online. Também foi testado neste modelo a influência das variáveis de preferência e uso de jornal impresso sobre o jornal online, mas elas, de maneira similar ao modelo de jornal impresso, não foram significativas.

\section{Discussão}

Contrariamente à proposição da estrutura de cinco atributos contemplada na escala proposta por Espártel (1999), uma estrutura de apenas dois fatores foi proposta para os itens da Escala de Avaliação de Atributos de Jornal. Não houve distinção entre atributos inicialmente propostos como atributos de jornal online e outros tidos como de jornal impresso. Essa indissociabilidade corrobora com Flavián e Gurrea (2007, 2009), com Lin, Salwen e Abdulla (2005) e Mings (1997), cujas pesquisas, de maneira geral, apresentaram estruturas semelhantes de motivação tanto para jornais impressos, quanto para jornais online. Flavián e Gurrea (2007) associam os atributos às estruturas motivacionais quando afirmam que os atributos são evidências pelas quais os consumidores avaliam se a motivação que perseguem pode ser satisfeita.

A etapa 2 propôs dois modelos relacionais, baseados no Modelo de Influência Cultural no Consumo (MICC) (Alfinito \& Torres, 2012), acrescidos de variáveis pertinentes ao mercado específico estudado (jornal), conforme explicitado nas Figuras 2 e 3. Com relação aos valores humanos e axiomas sociais como preditores, os resultados sugerem que, para o mercado de jornal, axiomas sociais não são tão relevantes como valores humanos, na perspectiva de avaliação do consumidor e para a amostra investigada. Consequentemente, o modelo das duas rotas de Allen (2000), seria, aparentemente, neste caso, suficiente para analisar as modalidades de jornal. Confrontando resultados anteriores com o MICC (Alfinito et al., 2016).

Nos dois modelos, as estruturas de todos os construtos adotados foi a mesma, permitindo uma avaliação mais controlada da comparação entre as duas modalidades de jornal. Todos os índices foram 
satisfatórios, conforme indicado por Marôco (2010). Em relação ao MICC (Alfinito \& Torres, 2012), a rota racional e indireta foi confirmada para o fator 1 dos atributos de jornal (Notícias), nos dois modelos. Essa rota era esperada, uma vez que o fator contém itens relacionados com as funções primárias de um jornal e sua distribuição para a população (Espártel, 1999). Contudo, o fator 2 dos atributos (Entretenimento) não fez parte da rota racional como esperado, uma vez que as relações entre Entretenimento e Julgamento Fragmentado não foram significativas em nenhum modelo. É interessante mencionar, no entanto, que quando incluído na rota afetiva, que deveria ser direta pela teoria e não passar por nenhum atributo (Allen \& Ng, 1999), as relações foram significativas, sugerindo rotas indiretas tanto para o julgamento fragmentado quanto para o julgamento afetivo. Esse resultado pode estar ligado às características dos atributos que compõem o fator Entretenimento, que apresentam características vinculadas a questões de lazer e estão mais próximos a valores de ordem individual, conforme previsto por Mittal (1988) em relação a escolhas afetivas do consumidor. Assim, para o melhor entendimento, elas serão referidas daqui em diante como rota afetiva $(\mathrm{VH}+\mathrm{AS}=>$ ATR2 $\Rightarrow$ JA) e rota racional $(\mathrm{VH}+\mathrm{AS}=>\mathrm{ATR} 1=>\mathrm{JF})$, ao invés de direta e indireta.

A relação entre Julgamento Fragmentado (JF) e Significado Utilitário (SU) não foi significativa, sendo o significado utilitário excluído nos dois modelos. Isto sugere que as experiências com o produto ou ainda os hábitos de consumo podem justificar que o consumidor não utilize processos de julgamento fragmentado avaliados pelo significado utilitário, no caso do jornal. Corrobora com essa suposição a motivação de hábito identificada nos estudos de Flavián e Gurrea (2007). Por outro lado, a predição de Julgamento Afetivo (JA) em relação ao Significado Simbólico (SS) foi bem forte, o que pode denotar aspectos subjetivos ligados ao consumo de informação e notícias que o jornal fornece, como prestígio e reconhecimento social (Chyi \& Lee, 2013; Richins, 1994).

Quanto à influência da rota racional, nota-se que ela não foi importante para o jornal impresso, mas foi determinante para o jornal online. E o contrário ocorreu para a rota afetiva, sendo ela determinante para o jornal impresso e não importante para o jornal online. Neste caso, a rota racional pode ser compreendida cumprindo dois papéis: para o jornal online, como uma variável dependente, sendo explicada pelo fator notícias de atributos de jornal; para o jornal impresso, representa um efeito indireto na relação entre os valores humanos+axiomas sociais e julgamento fragmentado. A respeito das diferentes rotas explicativas para cada modalidade de jornal é relevante destacar que esse resultado não corrobora as pesquisas realizadas sob a perspectiva de usos e gratificações (Flavián \& Gurrea, 2007, 2009; Lin et al. 2005; Mings, 1997), que encontraram estruturas de motivações semelhantes para leitores de jornais impressos e leitores de jornais online.

Adicionalmente, considerando a rota afetiva de explicação em relação ao jornal online, mediada pelo fator notícias dos atributos de jornal, este resultado corrobora a pesquisa de Flavián e Gurrea (2009), que identificou que os fatores (1) conhecimento sobre notícias atuais, (2) procura por informação específica, e (3) busca por novas notícias influenciam positivamente a atitude do leitor em relação ao jornal online. Há indícios, ainda, de uma predição da preferência por jornal online em seu consumo, resultado que corrobora os achados de Chyi e Lee (2013).

A oposição dos modelos identificados para jornal impresso e jornal online, perpassando diferentes fatores de atributos, indica uma tendência dos consumidores desta amostra a atribuírem a jornais impressos e jornais online significados distintos. Principalmente, por se tratarem aqui da mesma amostra que faz uso tanto de jornal online quanto de jornal impresso. A rota racional ligada a aspectos de facilidade, praticidade e meticulosidade para o uso do jornal online e a rota afetiva ligada a aspectos de tradição e afeto em relação ao uso do jornal impresso, além de prestígio social. Esse resultado vai ao encontro dos autores que defendem uma complementaridade entre as modalidades online e impressa (Nguyen \& Western, 2006; Stempel, Hargrove, \& Bernt, 2000). Para eles, a audiência de um meio busca satisfazer suas necessidades específicas e procura em cada meio aquilo que a satisfaz. Assim, cada modalidade pode servir a um propósito distinto. É plausível aceitar que finalidades distintas conduzam uma atribuição de significado também diferenciada entre os produtos impresso e online.

De acordo com Allen, $\mathrm{Ng}$ e Wilson (2002), a rota indireta contempla a avaliação racional do consumidor, em que os atributos são avaliados um a um até que se forme uma atitude global sobre o 
produto. Os modelos multi-atributos propõem que a influência dos valores nesta avaliação ocorre de forma direta (Fishbein \& Ajzen, 1975; Porto \& Torres, 2014). Neste estudo, foi possível testar essa influência direta, que não se mostrou significativa. Assim, identificou-se a presença de efeitos indiretos das variáveis julgamento fragmentado e julgamento afetivo na relação de valores humanos e axiomas sociais para frequência de uso de jornal.

No modelo estrutural 1, a relação entre os valores humanos e axiomas sociais e a frequência de uso de jornal impresso foi mediada pelo julgamento afetivo e a preferência por jornal impresso. Todavia, no modelo estrutural 2, esta relação foi mediada apenas pelo julgamento fragmentado, dando indícios de que as modalidades de jornal, impresso e online, sejam percebidos de maneira diferente pelos consumidores. Ainda no modelo 2, a preferência por jornal impresso não impactou a frequência de uso do jornal online, o que contraria a suposição de Chyi e Lee (2013) de que possa haver pessoas que preferem a modalidade de jornal impresso, mas acabam consumindo a modalidade online. Assim, os resultados demonstram que há uma tendência de avaliação do jornal impresso a partir da rota afetiva e a partir da rota racional para o jornal online. Alfinito e Torres (2012) comentam que o julgamento afetivo está mais vinculado com as crenças gerais mais abstratas do indivíduo, assim a influência dos valores humanos e axiomas sociais sugere ser mais forte para o jornal impresso do que para o online.

Este estudo traz um avanço na investigação dos fenômenos de consumo de jornal ao propor dois modelos amplos e comparativos em relação aos atuais modelos propostos na literatura que abarcam esse tema. A consideração concomitante de variáveis psicossociológicas como valores humanos e axiomas sociais, variáveis atitudinais e de comportamento, revelou implicações inéditas para este mercado. Ou seja, pela primeira vez foram associados construtos motivacionais e crenças gerais ao comportamento de consumo e preferência pelas modalidades impressa e online de jornal, essa incursão culminou na constatação empírica de que o consumidor de jornal considera o produto tanto do ponto de vista racional, por meio da avaliação passo a passo dos atributos ligados a notícias, quanto do ponto de vista afetivo, avaliando atributos ligados ao entretenimento e conferindo ao produto um significado simbólico, a depender da modalidade de jornal. Ao contrário do que se discute em pesquisas sob a perspectiva de usos e gratificações, a escolha do consumidor parece não ser somente consciente e racional. Nesse sentido, esses resultados implicam que a abordagem de usos e gratificações, embora seja mais popular para investigação do tema (Chyi \& Lasorsa, 1999; Flavián \& Gurrea, 2009), apresenta lacunas com importantes implicações práticas.

Ao suprimir a escolha subjetiva, afetiva e inconsciente do consumidor, são perdidas oportunidades de diferenciação no mercado. Alfinito e Torres (2012) reforçam que as empresas devem captar as diferenças mais sutis que envolvem a relação dos consumidores com seus produtos para que possam verdadeiramente se diferenciar dos produtos concorrentes. Portanto, considerar a parcela de comportamento do consumidor que é orientada por princípios diferentes das lógicas racionais pode contribuir para um melhor posicionamento de marcas e produtos no mercado de jornais, com implicações nos sistemas de relacionamento e percepção de satisfação.

Um possível caminho para perseguir estratégias nesse sentido pode ser o tipo de julgamento para cada modalidade de jornal. Independente da influência direta ou não do julgamento afetivo em cada modelo, a relação julgamento afetivo/significado simbólico, foi mais expressiva nos dois modelos, que a relação julgamento fragmentado/significado utilitário. Mittal (1988) destaca que o julgamento afetivo cumpre papel fundamental na formação da preferência de produtos, o que ficou muito claro para o jornal impresso. Assim, para esta modalidade, o julgamento simbólico, por estar desvinculado às características do produto e atrelado às características do consumidor, apresenta-se como um caminho interessante para buscar a diferenciação frente ao mercado consumidor desta modalidade.

O julgamento fragmentado, por outro lado, foi determinante para o jornal online. Este julgamento leva mais em consideração os atributos tangíveis do produto e grandes diferenças entre produtos são mais difíceis de ser estabelecidas, já que o mercado apresenta, de maneira geral, soluções de produtos relativamente homogêneos quanto aos jornais online. Assim, para esta modalidade, devem seguir o caminho oposto, potencializando facilidade de acesso e em diferentes canais para o aumento do uso do consumidor.

RAC, Rio de Janeiro, v. 23, n. 1, art. 2, pp. 23-42, janeiro/fevereiro, 2019, http://rac.anpad.org.br (ca) 


\section{Considerações Finais}

As reflexões instigadas pelos resultados alcançados na presente pesquisa, certamente suscitam um aprofundamento. No entanto, é possível perceber que os modelos adaptados do MICC conseguiram explicar parte do comportamento de frequência de uso, tanto do jornal impresso quanto do jornal online. Para o jornal impresso, essa relação foi afetiva e só foi possível por intermédio da preferência por jornal impresso. Para o jornal online, essa relação foi racional, sem a mediação da preferência por jornal online, mas sob sua influência direta. Esses resultados sugerem que o papel do jornal frente às motivações e crenças gerais que orientam o comportamento de escolha e consumo, podem ser mais claramente identificados que o próprio papel do jornal, principalmente para o jornal impresso. Isto reforça as oportunidades de geração de afinidade entre empresas, marcas e consumidores, por meio dos anseios e diferenças mais profundas ou subjetivas entre os consumidores. Vale destacar que, ainda que a amostra não possua caráter de generalização universal, por ter sido não probabilística, com distribuição por meio de redes sociais, confere indícios do comportamento dos leitores de jornais, online e impresso, acerca de suas preferências e como julgam as características de cada uma das modalidades de jornal.

Uma contribuição teórica relevante do estudo, refere-se ao MICC. Os axiomas sociais não demonstraram grande força como sugere o modelo. Adicionalmente, a rota afetiva não se confirmou como o esperado no modelo conceitual. Uma rota afetiva indireta foi sugerida, com VH+AS sendo mediado totalmente pelo Fator 2 de atributos (Entretenimento). Esse resultado indica que para o produto jornal a rota afetiva não se confirma como direta, conforme proposto no MICC. Para essa amostra, a avaliação de atributos media a relação entre os valores humanos e axiomas sociais e o julgamento afetivo, esse resultado pode indicar que os atributos componentes do Fator 2 podem ser atributos tidos como intangíveis pelo consumidor. Além disso, permite ampliar o entendimento do MICC de acordo com cada mercado específico. Ou seja, apesar de manter as dimensões afetiva e racional previstas na teoria, elas podem apresentar ou não uma rota direta entre as variáveis motivacionais e as escolhas ou preferências do consumidor daquele mercado.

Como implicações gerenciais, uma vez que os resultados sugerem que o julgamento é afetivo para o jornal impresso e racional para o jornal online, indica-se que o posicionamento de ambos obedeça às características identificadas para cada um. Ou seja, para o jornal impresso, deve haver um posicionamento psicológico, em que os sentimentos e as características intangíveis e simbólicas sejam valorizados pela associação entre as diferentes modalidades de jornais e perfís específicos do consumidor. Para o jornal online, um posicionamento por benefício e uso, em que as características tangíveis e de utilidade sejam valorizadas (e.g., menor impacto ambiental no uso de jornal online).

Embora a pesquisa se configure como uma tentativa de congregar recortes que estavam sendo observados na literatura separadamente, a amplitude do fenômeno não foi completamente abordada. É recomendado que pesquisas futuras contemplem, além dos construtos tratados neste trabalho, outros que visem melhorar o entendimento da leitura online e que estão sendo consideradas na literatura como variáveis que se relacionam com a adoção desse meio. Entre eles estão: o nível de acesso e familiaridade com o meio internet; o nível de utilização de outras mídias tradicionais além do jornal, como a televisão e o rádio; o comportamento de busca de conteúdo no meio online separadamente e em conjunto com o nível de envolvimento com determinado conteúdo nas mídias tradicionais e no meio online e a intenção de pagamento para utilização dos meios.

Do ponto de vista do emprego de medidas, nota-se uma limitação quanto à medida utilizada para acessar o comportamento de leitura. A utilização da frequuência de leitura, embora seja amplamente adotada na literatura, é criticada por Malthouse e Calder (2006) que orientam que a leitura deve ser trabalhada como uma variável latente. Para os autores, a frequência de leitura é apenas uma manifestação da leitura e sozinha não é capaz de acessar todo o comportamento de leitura. É sugerido que pesquisas posteriores ampliem a forma de apreciar a leitura seguindo tais considerações.

A respeito dos procedimentos de amostragem e coleta de dados, é relevante destacar que, ainda que a amostra tenha perfil sociodemográfico semelhante à população de leitores de jornal impresso e

RAC, Rio de Janeiro, v. 23, n. 1, art. 2, pp. 23-42, janeiro/fevereiro, 2019, http://rac.anpad.org.br (cc) 
online no Brasil, a técnica de amostragem foi não probabilística, com distribuição por meio de redes sociais, o que reduz a capacidade de extrapolação dos resultados. Dessa forma, sugere-se que novas pesquisas priorizem procedimentos de amostragem mais acurados, considerando, além da aleatoriedade, a estratificação da população nas regiões conforme a penetração do jornal impresso ou online.

Ademais, é indicado que pesquisas considerando os construtos motivacionais de valores humanos e axiomas sociais sejam conduzidas e aprofundadas na verificação do comportamento de consumo de outras mídias no contexto brasileiro e internacional oferecendo uma alternativa aos paradigmas dominantes na observação desses fenômenos.

\title{
Material Suplementar
}

Todos os dados e materiais foram disponibilizados publicamente por meio da plataforma Mendeley e podem ser acessados em: Alfinito, Solange (2018), "Data for Online and printed newspaper consumption published by RACRevista de Administração Contemporânea", Mendeley Data, v1http://dx.doi.org/10.17632/cbw7rr72mn.1

\section{Contribuições}

\author{
$1^{\circ}$ autor: Coleta de dados, proposta de pesquisa, desenho da pesquisa, redação inicial do referencial teórico, pesquisa qualitativa \\ e análises iniciais. \\ $2^{\circ}$ autor: Texto final, revisão das análises, produção do método e desenvolvimento da discussão e conclusões. \\ $3^{\circ}$ autor: Modelo estatístico, análises quantitativas e redação dos resultados de pesquisa.
}

\section{Referências}

Alfinito, S., Nepomuceno, M. V., \& Torres, C. V. (2012). Advances on the measure of judgment and meaning of the product for Brazil. Revista Brasileira de Marketing, 11(2), 148-173. http://doi.org/10.5585/remark.v11i2.2279

Alfinito, S., Siqueira, M. B., \& Torres, C. V. (2016). The student's choice based on consumer psychology: An analysis applied to higher education institutions of Brazil. International Review on Public and Nonprofit Marketing, 13(2), 185-201. http://doi.org/10.1007/s12208-016-0160-0

Alfinito, S., \& Torres, C. V. (2012). Modelo de influência cultural no consumo: Uma proposta baseada em axiomas sociais. Revista de Administração Mackenzie, 13(5), 15-38. http://doi.org/10.1590/S1678-69712012000500002

Allen, M. W. (2000). The attribute-mediation and product meaning approaches to the influences of human values on consumer choices. In F. Columbus (Org.), Advances in psychology research (Vol. 1, pp. 33-76). Huntington, NY: Nova Science Publishers.

Allen, M. W., Ng, S. H., \& Wilson, M. (2002). A functional approach to instrumental and terminal values and the value-attitude-behaviour system of consumer choice. European journal of Marketing, 36(1/2), 111-135. https://doi.org/10.1108/03090560210412728

Allen, M. W., \& Ng, S. H. (1999). The direct and indirect influences of human values on product ownership. Journal of Economic Psychology, 20(1), 5-39. https://doi.org/10.1016/S0167$\underline{4870(98) 00041-5}$ 
Assumpção, M. D. (2013). O consumo de jornal online: Um estudo baseado em valores humanos, axiomas sociais, preferências e uso de jornal impresso (Dissertação de mestrado). Universidade de Brasília, Brasília, DF, Brasil.

Bitner, J. R. (1989). Mass communication: An introduction. Englewood Cliffs, NJ: Prentice Hall.

Bond, M. H., Leung, K., Au, A., Tong, K., \& Chemonges-Nielson, Z. (2004). Combining social axioms with values in predicting social behaviours. European Journal of Personality, 18(3), 177-191. https://doi.org/10.1002/per.509

Castro, B. G. A., Torres, C. V., Nascimento, T. G., \& Demo, G. (2015). Are men more rational than women when purchasing cars? A comparison of cultural influences on product judgment in Brazil and the United States of America. Brazilian Business Review, 12(6), 72-99. https://doi.org/10.15728/bbr.2015.12.6.4

Chen, S. X., Lam, B. C. P., Wu, W. C. H., Ng, J. C. K., Buchtel, E. E., Guan, Y., \& Deng, H. (2016). Do people's world views matter? The why and how. Journal of Personality and Social Psychology, 110(5), 743-765. https://doi.org/10.1037/pspp0000061

Chyi, H. I. (2012). Paying for what? How much? And why (not)? Predictors of paying intent for multiplatform newspapers. International Journal on Media Management, 14(3), 227-250. https://doi.org/10.1080/14241277.2012.657284

Chyi, H. I., \& Chang, H. C. (2009). Examining the use of and preference for online news in the context of intermedia competition. In L. Leung, A. Fung, \& P. S. N. Lee (Eds.), Embedding into our lives: New opportunities and challenges of the Internet (pp. 101-123). Hong Kong: Chinese University Press.

Chyi, H. I., \& Lasorsa, D. L. (1999). Access, use and preference for online newspapers. Newspaper Research Journal, 20(4), 2-13. https://doi.org/10.1177/073953299902000401

Chyi, H. I., \& Lee, A. M. (2013). Online news consumption: A structural model linking preference, use, $\begin{array}{lllll}\text { and paying intent. Digital Journalism, } & \text { 1(2), } & \text { 194-211. }\end{array}$ https://doi.org/10.1080/21670811.2012.753299

Cieciuch, J., \& Schwartz, S. H. (2012). The number of distinct basic values and their structure assessed by PVQ-40. Journal of personality assessment, 94(3), 321-328. https://doi.org/10.1080/00223891.2012.655817

Deleersnyder, B., Dekimpe, M. G., Sarvary, M., \& Parker, P. M. (2004). Weathering tight economic times: The sales evolution of consumer durables over the business cycle. Quantitative Marketing and Economics, 2(4), 347-383. https://doi.org/10.1007/s11129-004-0137-x

Deleersnyder, B., Geyskens, I., Gielens, K., \& Dekimpe, M. (2002). How cannibalistic is the internet channel? A study of the newspaper industry in the United Kingdom and The Netherlands. International Journal of Research in Marketing, 19(4), 337-348. https://doi.org/10.1016/S01678116(02)00099-X

Demo, G., \& Guanabara, M. (2015). Relationship marketing with Apple: The role of meaning and judgment of product in choosing the iPhone. Revista Eletrônica de Administração, 21(1), 170199. Recuperado de http://www.scielo.br/pdf/read/v21n1/1413-2311-read-21-01-00170.pdf. http://doi.org/10.1590/1413-2311.0042014.46930

Espártel L. B. (1999). Atributos de produto e motivações de compra no mercado jornalístico do Rio Grande do Sul (Dissertação de mestrado). Escola de Administração. Universidade Federal do Rio do Grande do Sul, Porto Alegre, Brasil.

Fishbein, M., \& Ajzen, I. (1975). Belief, attitude, intention, and behavior: An introduction to theory and

RAC, Rio de Janeiro, v. 23, n. 1, art. 2, pp. 23-42, janeiro/fevereiro, 2019, http://rac.anpad.org.br (cc) 
research. Reading, MA: Addison-Wesley.

Flavián, C., \& Gurrea, R. (2007). Exploring the influence of reading motivations on perceived substitutability between digital and traditional newspapers. International Journal of Market Research, 9(2), 19-21. http://doi.org/10.1257/aer.97.3.713

Flavián, C., \& Gurrea, R. (2009). Users' motivations and attitude towards the online press. Journal of Consumer Marketing, 26(3), 164-174. https://doi.org/10.1108/07363760910954109

Gentzkow, M. (2007). Valuing new goods in a model with complementarities: Online newspapers. American Economic Review, 97(3), 713-744. https://doi.org/10.1257/aer.97.3.713

Ghosh, S. (1998). Making business sense of the internet. Harvard Business Review, 76(2), 126-135.

Gibbs, G. R. (2008). Analysing qualitative data. New York, NY: Sage.

Gilbert, C. (2001). A dilemma in response: Beyond resource allocation. Examining the newspaper industry's response to the internet (Tese de doutorado). Harvard Business School, Cambridge, Reino Unido.

Hair, J. F., Black, W. C., Babi, B. J., Anderson, R. E., \& Tatham, R. L. (2009). Análise multivariada de dados (6a ed.). Porto Alegre: Bookman.

Hill, M., Hill, R. (2008). Investigação por questionário. Lisboa: Edições Silabo.

IBOPE Inteligência. (2017). Pesquisas. Recuperado de http://www.ibopeinteligencia.com/noticias-epesquisas

Ipsos Marplan. (2017). Plataformas de mensuração \& entendimento de audiência. Recuperado de https://www.ipsos.com/pt-br/plataformas-de-mensuracao-entendimento-de-audiencia.

Kahneman, D. (2011). Thinking, fast and slow. New York, NY: Macmillan.

Kline, R. B. (2015). Principles and practice of structural equation modeling (4th ed). New York, NY: The Guilford Press.

Leung, K., Au, A., Huang, X., Kurman, J., Niit, T., \& Niit, K. (2007). Social axioms and values: A cross-cultural examination. European Journal of Personality, 21(2), 91-111. http://doi.org/10.1002/per.615

Leung, K., \& Bond, M. H. (2008). Psychologic and ecologic: Insights from social axiom dimensions. In F. Van De Vijver, D. Van Hemert, \& Y. P. Poortinga (Eds.), Individuals and cultures in multilevel analysis (pp. 197-219). Mahwah, NJ: Lawrence Erlbaum Associates.

Leung, K., Bond, M. H., Carrasquel, S. R. de, Muñoz, C., Hernández, M., Murakami, F., Yamaguchi, S., Bierbrauer, G., Singelis, T. M. (2002). Social axioms: The search for universal dimensions of general beliefs about how the world functions. Journal of Cross-Cultural Psychology, 33(3), 286302. https://doi.org/10.1177/0022022102033003005

Leung, K., Lam, B. C., Bond, M. H., Conway, L. G., III, Gornick, L. J., Amponsah, B., ... \& Busch, H. (2012). Developing and evaluating the social axioms survey in eleven countries: Its relationship with the five-factor model of personality. Journal of Cross-Cultural Psychology, 43(5), 833-857. http://doi.org/10.1177/0022022111416361

Lin, C., Salwen, M. B., \& Abdulla, R. A. (2005). Uses and gratification of online and offline news: New wine in old bottles? In M. B. Salwen, B. Garrison, \& P. D. Driscoll (Eds.), Online news and the public (pp. 221-236). Mahwah, NJ: Lawrence Erlbaum Associates.s

Luppe, M. R., \& Angelo, C. F. de (2010). As decisões de consumo e a heurística da ancoragem: Uma

RAC, Rio de Janeiro, v. 23, n. 1, art. 2, pp. 23-42, janeiro/fevereiro, 2019, http://rac.anpad.org.br (cc) 
análise da racionalidade do processo de escolha. Revista de Administração Mackenzie, 11(6), 81106. http://doi.org/10.1590/S1678-69712010000600006

Malthouse, E. C., \& Calder, B. J. (2006). Demographics of newspaper readership: Predictors and patterns of US consumption. Journal of Media Business Studies, 3(1), 1-18. https://doi.org/10.1080/16522354.2006.11073436

Marôco, J. (2010). Análise de equações estruturais: Fundamentos teóricos, software \& aplicações. Pêro Pinheiro: ReportNumber.

Mcquail, D. (2004). Mass communication theory: an introduction (3rd ed). London: Sage

Mings, S. M. (1997). Uses and gratifications of online newspapers: A preliminary study. The Electronic Journal of Communication, 7(3). Retrieved from http://www.cios.org/www/ejc/v7n397.htm

Mittal, B. (1988). The role of affective choice mode in the consumer purchase of expressive products. Journal of Economic Psychology, 9(4), 499-524. https://doi.org/10.1016/0167-4870(88)90016-5

Mitchelstein, E., \& Boczkowski, P. J. (2010). Online news consumption research: An assessment of past work and an agenda for the future. New Media \& Society, 12(7), 1085-1102. https://doi.org/10.1177/1461444809350193

Nguyen, A., \& Western, M. (2006). The complementary relationship between the internet and traditional mass media: The case of online news and information on traditional sources. Information Research, 11(3), 3-11.

Pasquali, L. (2005). Análise fatorial para pesquisadores. Brasília: LabPAM.

Pimenta, M. L., \& Piato, É. L. (2016). Cognitive relationships between automobile attributes and personal values. Asia Pacific Journal of Marketing and Logistics, 28(5), 841-861. https://doi.org/10.1108/APJML-09-2015-0147

Porto, R. B., \& Torres, C. V. (2014). Valores humanos como moderadores e supressores na preferência do consumidor por marcas e produtos. Estudos de Psicologia, 19(2), 91-101. http://doi.org/10.1590/S1413-294X2014000200001

Richins, M. L. (1994). Special possessions and the expression of material values. Journal of consumer research, 21(3), 522-533. http://doi.org/10.1086/209415

Rife, S. C., Cate, K. L., Kosinski, M., \& Stillwell, D. (2016). Participant recruitment and data collection through Facebook: The role of personality factors. International Journal of Social Research Methodology, 19(1), 69-83.

Rogers, E. M. (2003). Diffusion of innovations (5th ed). Nova York, NY: Free Press.

Sagiv, L., Roccas, S., Cieciuch, J., \& Schwartz, S. H. (2017). Personal values in human life. Nature Human Behaviour, 1(9), 630-639. http://doi.org/10.1038/s41562-017-0185-3

Schwartz, S. (1992). Universalism in the content and structure of values: theoretical advances and empirical tests in 20 countries. In M. P. Zanna (Org.), Advances in experimental social psychology (Vol. 25, pp. 1-65). Orlando: Academic.

Schwartz, S. H., Cieciuch, J., Vecchione, M., Davidov, E., Fischer, R., Beierlein, C., ... \& DirilenGumus, O. (2012). Refining the theory of basic individual values. Journal of Personality and Social Psychology, 103(4), 663. http://doi.org/10.1037/a0029393

Skogerbø, E., \& Winsvold, M. (2011). Audiences on the move? Use and assessment of local print and online newspapers. European Journal of Communication, 26(3), 214-229. 
https://doi.org/10.1177/0267323111413112

Stempel, G. H., Hargrove, T., \& Bernt, J. P. (2000). Relation of growth of use of the internet to changes in media use from 1995 to 1999. Journalism \& Mass Communication Quarterly, 77(1), 71-79. https://doi.org/10.1177/107769900007700106

Strasheim, A., \& Ungerer L. (2017). An alternative model of Schwartz's basic human values in consumer research. In C. L. Campbell (Ed.), The customer is not always right? Marketing orientationsin a dynamic business world (pp. 814-814). Cham: Springer.

Thurman, N. (2018). Newspaper consumption in the mobile age: Re-assessing multi-platform performance and market share using "time-spent". Journalism Studies, 19(10), 1409-1429. https://doi.org/10.1080/1461670X.2017.1279028

Thurman, N., \& Fletcher, R. (2017). Has digital distribution rejuvenated readership? Revisiting the age demographics of newspaper consumption. Journalism Studies, 18(1), 1-21. https://doi.org/10.1080/1461670X.2017.1397532

Torres, C. V., \& Allen, M. W. (2009a). Human values and consumer choice in Australia and Brazil. Psicologia: Teoria e Pesquisa, 25(4), 489-497. http://doi.org/10.1590/S010237722009000400004

Torres, C. V., \& Allen, M. W. (2009b). Influência da cultura, dos valores humanos e do significado do produto na predição de consumo: Síntese de dois estudos multiculturais na Austrália e no Brasil. Revista de Administração Mackenzie, 10(3), 127-152. http://doi.org/10.1590/S167869712009000300008

Torres, C. V., Schwartz, S. H., \& Nascimento, T. G. (2016). A teoria de valores refinada: Associações com comportamento e evidências de validade discriminante e preditiva. Psicologia USP, 27(2), 341-356. http://doi.org/10.1590/0103-656420150045

Wegener, D. T., Petty, R. E., Blankenship, K. L., \& Detweiler-Bedell, B. (2010). Elaboration and numerical anchoring: Implications of attitude theories for consumer judgment and decision making. Journal of Consumer Psychology, 20(1), 5-16. https://doi.org/10.1016/j.jcps.2009.12.003

Zajonc, R. B. (1980). Feeling and thinking: Preferences need no inferences. American psychologist, 35(2), 151-175. http://doi.org/10.1037/0003-066X.35.2.151

\section{Autores}

Marilia Assumpção

EUPS 703/903, lote A, 70000-000, Brasília, DF, Brasil.

E-mail: mariliaassumpcao@gmail.com

Solange Alfinito

Campus Darcy Ribeiro Prédio da FACE PPGA, 70910-900, Brasília, DF, Brasil.

E-mail: salfinito@unb.br

Breno Giovanni Adaid Castro

SGAN Quadra 609, Módulo D, L2 Norte, 70.830-404, Brasília, DF, Brasil.

E-mail: brenoadaid@gmail.com 